\title{
Argirein alleviates stress-induced and diabetic hypogonadism in rats via normalizing testis endothelin receptor $A$ and connexin 43
}

\author{
Ming $\mathrm{XU}^{1, \#}$, Chen $\mathrm{HU}^{1, \#}$, Hussein-hamed $\mathrm{KHAN}^{1,4}$, Fang-hong SHI ${ }^{1,2}$, Xiao-dong CONG ${ }^{3}$, Qing $\mathrm{LI}^{1}$, Yin DAl ${ }^{1}$, De-zai DAl ${ }^{1, *}$
}

${ }^{1}$ Research Division of Pharmacology, China Pharmaceutical University, Nanjing 210009, China; ${ }^{2}$ Department of Pharmacy, Renji Hospital, School of Medicine, Shanghai Jiaotong University, Shanghai 200127, China; ${ }^{3} Z$ hejiang University of Traditional Medicine, Hangzhou 311401, China; ${ }^{4}$ Department of Pharmacology, University of Adam, Yemen

Aim: Argirein (rhein-arginine) is a derivative of rhein isolated from Chinese rhubarb (Rheum Officinale Baill) that exhibits antioxidant and anti-inflammatory activities. In the present study we investigated the effects of argirein on stress-induced (hypergonadotrophic) and diabetic (hypogonadotrophic) hypogonadism in male rats.

Methods: Stress-induced and diabetic hypogonadism was induced in male rats via injection of isoproterenol (ISO) or streptozotocin (STZ). ISO-injected rats were treated with argirein $\left(30 \mathrm{mg} \cdot \mathrm{kg}^{-1} \cdot \mathrm{d}^{-1}, \mathrm{po}\right)$ or testosterone replacement $\left(0.5 \mathrm{mg}^{\mathrm{kg}} \mathrm{kg}^{-1} \cdot \mathrm{d}^{-1}, \mathrm{sc}\right)$ for $5 \mathrm{days}$, and STZ-injected rats were treated with argirein $\left(40-120 \mathrm{mg} \cdot \mathrm{kg}^{-1} \cdot \mathrm{d}^{-1}, \mathrm{po}\right)$ or aminoguanidine $\left(100 \mathrm{mg} \cdot \mathrm{kg}^{-1} \cdot \mathrm{d}^{-1}, \mathrm{po}\right)$ for $4 \mathrm{weeks}$. After the rats were euthanized, blood samples and testes were collected. Serum hormone levels were measured, and the expression of endothelin receptor $\mathrm{A}\left(\mathrm{ET}_{\mathrm{A}}\right)$, connexin $43(\mathrm{Cx} 43)$ and other proteins in testes was detected. For in vitro experiments, testis homogenate was prepared from normal male rats, and incubated with ISO $(1 \mu \mathrm{mol} / \mathrm{L})$ or high glucose $(27 \mathrm{mmol} / \mathrm{L})$.

Results: ISO injection induced hyper-gonadotrophic hypogonadism characterized by low testosterone and high FSH and LH levels in the serum, whereas STZ injection induced hypogonadotrophic hypogonadism as evidenced by low testosterone and low FSH and LH levels in the serum. In the testes of ISO- and STZ-injected rats, the expression of $\mathrm{ET}_{\mathrm{A}}, \mathrm{MMP}_{\mathrm{N}} \mathrm{9}, \mathrm{NADPH}$ oxidase and pPKCE was significantly increased, and the expression of $\mathrm{C} \times 43$ was decreased. Administration of argirein attenuated both the abnormal serum hormone levels and the testis changes in ISO- and STZ-injected rats, and aminoguanidine produced similar actions in STZ-injected rats; testosterone replacement reversed the abnormal serum hormone levels, but did not affect the testis changes in ISO-injected rats. Argirein (0.3-3 $\mu \mathrm{mol} / \mathrm{L}$ ) exerted similar effects in testis homogenate incubated with ISO or high glucose in vitro.

Conclusion: Two types of hypogonadism of male rats exhibit increased expression of $\mathrm{ET}_{\mathrm{A}}$ and depressed expression of $\mathrm{Cx} 43$ in testes, despite different patterns of serum FSH and LH. Argirein alleviates the two types of male hypogonadism via normalizing $\mathrm{ET}_{\mathrm{A}}$ and $\mathrm{Cx}_{4} 3$ in testes.

Keywords: argirein; rhein; male hypogonadism; hypergonadotrophic; hypogonadotrophic; $\mathrm{ET}_{\mathrm{A}}$; connexin 43; aminoguanidine; testosterone

Acta Pharmacologica Sinica (2016) 37: 246-254; doi: 10.1038/aps.2015.125; published online 18 Jan 2016

\section{Introduction}

The incidence of male hypogonadism is increasing in modern society; approximately $37.8 \%$ of males who are at least 45 years of age and visit a physician in the USA exhibit low testosterone in the serum $(<300 \mathrm{ng} / \mathrm{dL})^{[1]}$. Male patients, especially patients with obesity, diabetic mellitus ${ }^{[2]}$ or hypertension,

\footnotetext{
\#These authors contributed equally to this work.

* To whom correspondence should be addressed.

E-mail dezaidai@vip.sina.com

Received 2015-05-09 Accepted 2015-10-08
}

manifest a significant increase in the incidence of hypogonadism relative to the age-matched population. Stress caused by endurance physical training substantially contributes to male hypogonadism, in part, as a result of an overactive sympathetic nervous system ${ }^{[3]}$.

One feedback system, referred to as the hypothalamic-pituitary-gonadal axis (HPG axis), is critical in the maintenance of the normal functions of the testis; however, these functions may be functionally perturbed in cases of stress or hyperglycemia, which results in insufficient testosterone levels in association with altered follicle stimulating hormone (FSH) and 
luteinizing hormone (LH) in serum ${ }^{[4-6]}$.

Defects in testes that result from many causal factors and induce low serum testosterone require drug interventions to improve physical, psychological and social activities; current treatments have depended on testosterone replacement therapy $(\mathrm{TRT})^{[7,8]}$, which relieves the symptoms and signs by increasing testosterone in serum. It has not been fully elucidated whether TRT relieves the abnormal changes in a damaged testis.

Based on emerging data, male hypogonadism may result due to an increase in pro-inflammatory cytokines, including activated endothelin receptor $\mathrm{A}\left(\mathrm{ET}_{\mathrm{A}}\right)$ and reactive oxygen species (ROS), and impaired intracellular communication via depressed connexin 43 (Cx43), which may result from the activation of NADPH oxidase (NOX) in the testis ${ }^{[9-11]}$. Increasing evidence indicates that an overactivated $\mathrm{ET}_{\mathrm{A}}$ is intimately linked to the activation of NOX, which produces more ROS and plays an important role in many cardiovascular diseases, as well as the pathologies of dysfunctional testes ${ }^{[9]}$. Emerging data have suggested that the basal ET-1 level in patients with male hypogonadism is increased ${ }^{[12]}$, and our previous findings indicated that the ET-1, ECE (endothelin converting enzyme) and ROS levels are increased in thyrotoxicosis-induced testicular injury and altered in diabetic or adenine induced testopathy ${ }^{[11,13,14]}$. Matrix metalloproteinase-9 (MMP-9) has a primary role in the modulation of the amount of extracellular matrix responsible for the normal structure and functions of the seminiferous tubules ${ }^{[15]}$. Intracellular communication in the testis is unique for harmonizing testis function and is achieved by the normal expression of junctional protein connexin Cx43. Cx43 is severely affected by abnormal MMP-9, and its abnormality may participate in depressed steroidogenic acute regulatory

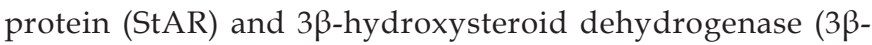
HSD) (two important enzymes responsible for testosterone biosynthesis); furthermore, increased Cx43 is associated with a recovery of low serum testosterone in male hypogonadism ${ }^{[15]}$. Therefore, it is interesting to investigate interventions that may relieve an abnormal testis, using two models of hypogonadism, via the normalization of increased $\mathrm{ET}_{\mathrm{A}}$ and decreased CX43 in testes.

Rhein is an effective ingredient that has been used in TCM (traditional Chinese medicine). It is isolated from Chinese rhubarb (Rheum Officinale Baill) and has been used alone ${ }^{[16]}$ or in a combined therapy ${ }^{[17]}$ in the treatment of diabetic nephropathy. The solubility of rhein is poor, and its $t_{1 / 2}$ is not sufficiently long; thus, chemical modification was conducted to improve its biological behaviors by connecting a moiety of $L$-arginine through a hydrogen bond. The novel compound exhibits antioxidant and anti-inflammatory activities with a prolonged $t_{1 / 2}{ }^{[18,19]}$. Following oral administration, the new compound argirein (rhein-arginine) releases both rhein and L-arginine, which may attenuate male hypogonadism with two patterns of gonadotrophic hormones.

We hypothesized that male hypogonadism is established by either sustained stress (as a result of isoproterenol administration) or diabetes (streptozotocin administration) in rats.
The two models of hypogonadism exhibit low testosterone and are different regarding the serum levels of FSH and LH. Upregulated $\mathrm{ET}_{\mathrm{A}}$, which is closely related to an activated NOX for ROS genesis ${ }^{[20]}$, may be upregulated to decrease the intracellular communication protein $\mathrm{Cx} 43^{[21]}$. In this study, we verified whether changes in $\mathrm{ET}_{\mathrm{A}}$ and $\mathrm{Cx} 43$ may occur in the pathologies of the two models of male hypogonadotrophic hypogonadism, and the effects of argirein (rhein-argirein) was compared with TRT in the normalization of these changes in stress-induced male hypogonadism. In the treatment of diabetic male hypogonadism, aminoguanidine (AMG) was employed as a positive reference, which attenuates oxidative stress in diabetic mellitus ${ }^{[22]}$.

\section{Materials and methods}

\section{Animals and chemicals}

Male Sprague-Dawley (SD) rats, $220 \pm 20 \mathrm{~g}$ in weight, were purchased from the Nanjing Experimental Animal Center and were maintained in a standard environment at a controlled temperature $\left(20-25^{\circ} \mathrm{C}\right)$. Each rat was provided $15 \mathrm{~g}$ of standard chow and clean water each day. The restriction of food was useful for improving general conditions in the untreated rats $^{[14]}$

Argirein (rhein-arginine) (Figure 1) was synthesized at the Center of Traditional Chinese Medicine Processing, which is affiliated with Zhejiang Traditional Chinese Medicine University. Isoproterenol (ISO) injection, testosterone propionate and streptozotocin (STZ) were purchased from Shanghai Harvest Pharmaceutical Company (Shanghai, China) and Sigma (St Louis, MO, USA), respectively.

\section{Two models of male hypogonadism in vivo}

One hundred and four male SD rats, 180-210 g, were randomly employed into two experiments:

1. Stress induced hypogonadism: Thirty-two rats were divided into 4 groups ( $n=8)$ : (1) normal; (2) ISO, $1 \mathrm{mg} / \mathrm{kg}$, sc for $10 \mathrm{~d}$; (3) and (4) ISO injected rats were administered $\left(\mathrm{mg} \cdot \mathrm{kg}^{-1} \cdot \mathrm{d}^{-1}, \mathrm{sc}\right)$ testosterone $(0.5)$ or argirein $(30)$, respectively, on the last 5 days.

2. Diabetic hypogonadism: Sixty male rats were employed in the second experiment of hypogonadism, which was induced by a dose of STZ $65 \mathrm{mg} / \mathrm{kg}$, ip ${ }^{[14]}$. After 3 weeks of blood glucose monitoring at one week intervals, a diabetic rat model was confirmed when hyperglycemia was greater than $16.7 \mathrm{mmol} / \mathrm{L}^{[14]}$. The biochemical and bioactive molecules were assessed at the end of 8 weeks. The intervention
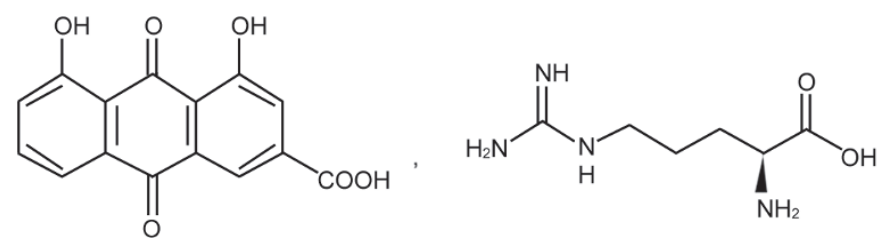

Figure 1. The chemical structure of rhein-arginine (argirein) compound shows a hydrogen bond connecting the two moieties. 
$\left(\mathrm{mg} \cdot \mathrm{kg}^{-1} \cdot \mathrm{d}^{-1}, \mathrm{po}\right)$ with argirein $(40,80$ and 120$)$ was compared with AMG (100) in the last 4 weeks. AMG has been demonstrated to be a positive drug to relieve diabetic lesions in rats $^{[22]}$. The experiment was conducted as follows: (1) normal; (2) STZ injected alone; (3) STZ injected and intervention with AMG; and (4), (5), and (6), intervened with multiple doses of argirein $\left(40,80\right.$ and $\left.120 \mathrm{mg} \cdot \mathrm{kg}^{-1} \cdot \mathrm{d}^{-1}\right)$. The normal and ISO or STZ treated rats were injected with $1 \%$ carboxymethylcellulose-Na (CMC-Na).

\section{Serum biochemical measurements}

The rats were anesthetized with urethane $1.5 \mathrm{~g} / \mathrm{kg}$ ip and were euthanized via carotid artery bleeding on day 11 in experiment 1 or at the end of 8 weeks in experiment 2 . The blood samples were collected, and the testes were harvested and stored in liquid nitrogen for subsequent analysis via PCR and Western blotting assays. Serum was collected to measure testosterone, FSH (follicle stimulating hormone) and LH (luteinizing hormone) with radioimmunoassays according to the manufacturer's instructions (Jiuding Medical Bio-engineering Company, Tianjin, China).

\section{Two models in vitro}

Twelve male rats were euthanized via cervical dislocation, and the testes were collected. The incubation of testis homogenate was produced at a ratio of 1:3 with $\mathrm{KH}$ solution, according to a previously reported method with modifications ${ }^{[23]}$. In the experiment, the testis homogenate was employed to replace the isolated Leydig cells to investigate changes in the testis damaged by ISO or high glucose, and the beneficial effects were identified following argirein administration. An aliquot of the homogenate $(0.3 \mathrm{~mL})$ was distributed into two different experiments, which included RT-PCR and Western blotting assays, following incubation at $37^{\circ} \mathrm{C}$ for $4 \mathrm{~h}$ as follows:

1. ISO incubation: 1) Normal group; 2) ISO group (1 $\mu \mathrm{mol} / \mathrm{L}$ ); and 3 ) argirein (rhein-arginine) group (ISO+rheinarginine $0.3,1.0$ and $3.0 \mu \mathrm{mol} / \mathrm{L}$ ).

2. High glucose incubation: 1) Normal group; 2) High glucose group (27 mmol/L); and 3) Argirein group (high glucose + rhein-arginine $0.3,1.0$, and $3.0 \mu \mathrm{mol} / \mathrm{L}$ ).

To further examine the efficacy of the argirein intervention in the two models in vitro, the effects were verified to occur in a dose-dependent and time-dependent manner.

\section{RT-PCR}

The mRNA expression of $\mathrm{ET}_{\mathrm{A}}$, NOX p47phox, MMP-9, Cx43 and $\mathrm{PKC} \varepsilon$ was determined with reverse transcriptase polymerase chain reaction (RT-PCR $)^{[11]}$. The process was performed as briefly described. Total mRNA was extracted from the homogenate of the testis or an aliquot of the incubated medium with TRIzol Plus (Biouniquer Technology Company, Nanjing, China). The reverse transcription was performed with a BU-Script KIT(50) (Biouniquer Technology Company, Nanjing, China) as follows (in $20 \mu \mathrm{L}$ ): $4 \mu \mathrm{L} 5 \times$ BU-Script buffer, $1 \mu \mathrm{L}$ dNTP mix (10 mmol/L), $1 \mu \mathrm{L}$ Oligo $(\mathrm{dT})_{18}(10 \mathrm{pmol} / \mu \mathrm{L}), 1$ $\mu \mathrm{L} 20 \mathrm{U} / \mu \mathrm{L}$ RNase Inhibitor, $1 \mu \mathrm{L} 20 \mathrm{U} / \mu \mathrm{L}$ BU-Script Reverse
Transcriptase and $2 \mu \mathrm{L}$ total RNA $(1 \mu \mathrm{g} / \mu \mathrm{L})$ and DEPC water were added to adjust the final volume to $20 \mu \mathrm{L}$. The prepared mixture was reversely transcribed to cDNA under the following conditions described in brief: 1) $30^{\circ} \mathrm{C}, 10 \mathrm{~min}$; 2) $42{ }^{\circ} \mathrm{C}, 60$ min; 3) $99^{\circ} \mathrm{C}, 5 \mathrm{~min}$; and 4$) 4{ }^{\circ} \mathrm{C}, 5 \mathrm{~min}$. The cDNA products were subject to PCR reaction, and the PCR products were processed in parallel with $\beta$-actin. The band densities were analyzed using Labworks imaging acquisition and analysis software (GDS8000, Syngene, England).

\section{Western blotting}

The quantitative analysis of the $\mathrm{ET}_{\mathrm{A}}$, NOX p47phox, Cx43, PKC $\varepsilon$ and peroxisome proliferator activated receptor a (PPARa) proteins was performed as previously described ${ }^{[13]}$. In brief, $200 \mathrm{mg}$ of testis tissue was homogenized with $800 \mu \mathrm{L}$ of lysis buffer (mmol/L) at $\mathrm{pH} 7.4$, which comprised HEPES 20, 0.1\% Triton X-100, NaCl 25, EGTA 2 and phenylmethylsulphonyl fluoride 1 , and centrifuged at $12000 \mathrm{r} / \mathrm{min}$ for 10 $\mathrm{min}$. An aliquot of the supernatant or the incubated medium was processed for the subsequent analyses. The prepared protein solution was conducted on sodium dodecyl sulfate polyacrylamide gel electrophoresis (SDS-PAGE), transferred onto nitrocellulose, blocked with nonfat milk $(5 \% w / v)$, and subsequently incubated with primary and secondary antibodies sequentially: the primary antibodies included polyclonal goat anti-ET $\mathrm{A}_{\mathrm{A}}-\mathrm{IgG}$ (Wuhan Boster Biological Technology, China), polyclonal rabbit anti-NOX p47phox-IgG (Affinity Bioreagents, USA), polyclonal rabbit anti-MMP-9-IgG (Wuhan Boster Biological Technology, China), polyclonal rabbit anticonnexin 43-IgG (Wuhan Boster Biological Technology, China), polyclonal rabbit anti-phosphorylated-PKCE (Ser729)IgG and anti-PPARa (Upstate, USA), and polyclonal rabbit anti-Actin-IgG (Wuhan Boster Biological Technology, China); horseradish peroxidase-conjugated IgG was used as the secondary antibody (Wuhan Boster Biological Technology). Antigen was detected with a 3,3'-diaminobenzidine (DAB) kit (Wuhan Boster Biological Technology, China), and the samples were subsequently processed in parallel with $\beta$-actin. The density of the bands was analyzed using Labworks imaging acquisition and analysis software (GDS8000, Syngene, England).

\section{Statistical analysis}

Sigma Plot 9.0 (SPSS Inc, USA) was applied for the data processing, and the results were presented as the mean \pm SD. Student's $t$-test was used to determine the statistical significance for differences between two mean values, and a one-way analysis of variance (ANOVA) was used followed by a Bonferroni test. The difference was considered statistically significant at $P<0.05$.

\section{Results}

\section{Serum testosterone, FSH and LH following ISO administration}

Following ISO administration for 10 days, the serum testosterone level was significantly decreased $(P<0.01)$, which indicated a status of hypogonadism, and was accompanied by signifi- 

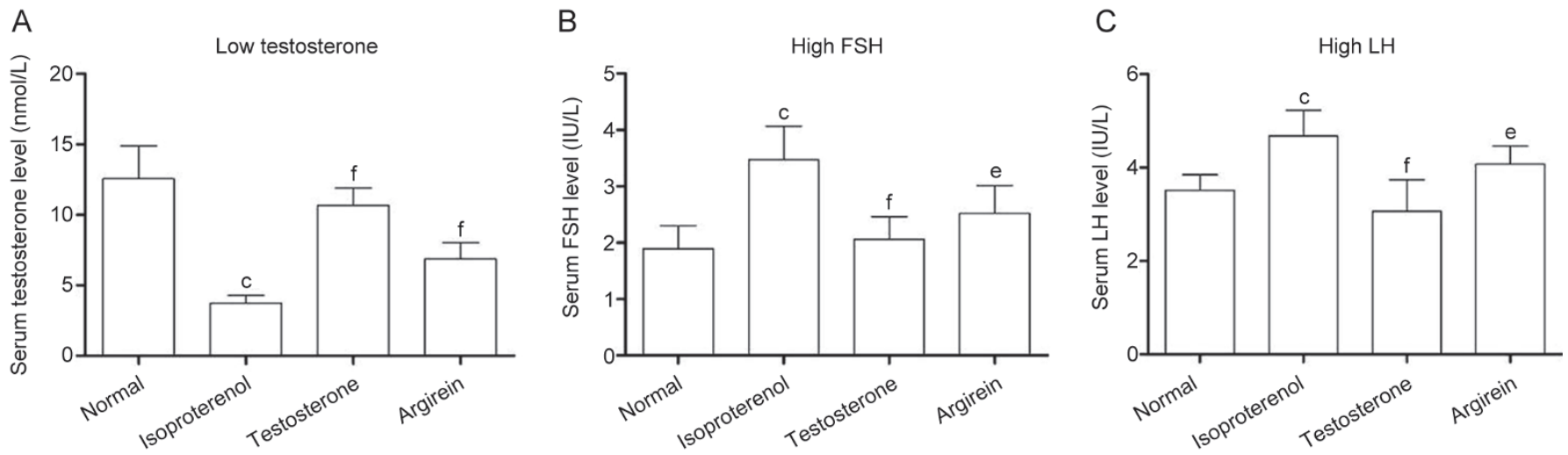

Figure 2. Testis deficiency in ISO-injected rats: decreased testosterone and high FSH and LH in serum presented the characteristics of hypergonadotrophic hypogonadism. These changes were ameliorated by argirein (rhein-arginine) and a supplement of testosterone by testosterone propionate. (A) Low testosterone; (B) High FSH; (C) High LH. Mean \pm SD. $n=8$. ${ }^{c} P<0.01$ vs normal. ${ }^{e} P<0.05,{ }^{f} P<0.01$ vs ISO.

cantly increased LH and FSH $(P<0.01)$ compared with normal. This finding indicated that the HPG axis responded well to a decrease in the serum testosterone by ISO, and a model of hypogonadotrophic hypogonadism was established. Following argirein (rhein-arginine) intervention for the last 5 days, these changes were substantially restored $(P<0.05, P<0.01)$ compared with ISO alone (Figure 2). Testosterone propionate induced a remarkable increase in the serum testosterone and reduced the increased FSH and LH in the serum.

\section{Abnormal $\mathrm{ET}_{\mathrm{A}}, \mathrm{NOX}, \mathrm{MMP}-9, \mathrm{PKC} \varepsilon$ and $\mathrm{Cx} 43$ in vivo}

The administration of ISO led to a series of changes in the testis, including a remarkable upregulation of the mRNA and protein levels of $\mathrm{ET}_{\mathrm{A}}$, NOX p47phox, MMP-9, and mRNA of PKC $\varepsilon$ and the protein ratio of $\mathrm{pPKC} \varepsilon / \mathrm{PKC} \varepsilon$, as well as a downregulation of $\mathrm{Cx} 43(P<0.01)$. These changes were alleviated following argirein administration in the last $5 \mathrm{~d}(P<0.01)$ compared with the ISO group. No response to testosterone supplementation was identified (Figure 3).

\section{Serum testosterone, FSH and $\mathrm{LH}$ in diabetic testis}

Eight weeks following a whole dose of STZ, the serum testosterone was significantly decreased; however, the FSH and LH responses were significantly decreased. The diabetic testis exhibited a hypogonadotrophic property, and the abnormalities were attenuated by AMG and argirein. In the serum, the insulin levels were significantly decreased, and there was no response to argirein or AMG (Figure 4).

\section{Abnormal $\mathrm{ET}_{\mathrm{A}}, \mathrm{Cx} 43$ and PPAR $\alpha$ in diabetic testis in vivo}

Diabetes led to male hypogonadism associated with changes in the testis as follows: upregulated mRNA and protein levels of $\mathrm{ET}_{\mathrm{A}}$ and downregulated mRNA and protein levels of Cx43 were identified $(P<0.01)$ relative to normal. Decreased PPARa was also associated with these changes. These changes were relieved by argirein and AMG administration in the last 4 weeks $(P<0.01)$ (Figure 5).

\section{$\mathrm{ET}_{\mathrm{A}}, \mathrm{NOX}$ and $\mathrm{Cx} 43$ in vitro}

In the present experiment, the testicular homogenate preparation was incubated with ISO or high glucose in vitro to mimic conditions under stress or diabetes, respectively. Following a short exposure for $4 \mathrm{~h}$, there was a significant upregulation of mRNA and a protein abundance of $\mathrm{ET}_{\mathrm{A}}$ and p47phox, whereas Cx43 was notably decreased in the two tests in vitro relative to normal $(P<0.05, P<0.01$, respectively). Significant relief was induced by argirein $(P<0.05, P<0.01$, respectively) compared with ISO or high glucose alone (Figure S1, Figure S2).

To test the effects induced by argirein in vitro, three doses were employed in the models of testis homogenate incubated with ISO or high glucose, respectively. Beneficial effects on upregulated $\mathrm{ET}_{\mathrm{A}}$ and NOX p47phox and decreased CX43 occurred in a dose-dependent manner in the two models (Figure 6,7). The experiment was conducted over time, and the variables were evaluated at three different time points. The results demonstrated a relief of abnormal CX43 in a time dependent manner in the two models (Figure 6, 7).

\section{Discussion}

The main findings indicated that the models of hypergonadotrophic and hypogonadotrophic hypogonadism were independently established by stress (ISO-injected) and diabetes (STZinjected) in rats, respectively. The abnormal serum hormone levels were significantly corrected following the administration of testosterone, argirein, and AMG, respectively.

The compromised biosynthesis of testosterone was a result of oxidative stress, which was caused by an activated NOX involved in the testis. A subtype of p47phox is required as an "organizer" protein, which is necessary in the process of full NOX activation ${ }^{[24]}$. The interaction of $\mathrm{p} 47$ phox with other components, such as p22phox, further facilitates the full activation of the oxidase ${ }^{[25]}$. An activation of NOX p47phox in diabetic nephropathy was identified in relation to $\mathrm{ET}_{\mathrm{A}}$ activation and was suppressed by the endothelin receptor antagonist CPU0213, which indicates a close link between the ET system 
A

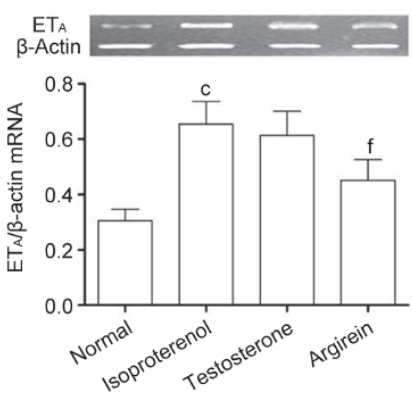

$\mathrm{E}$
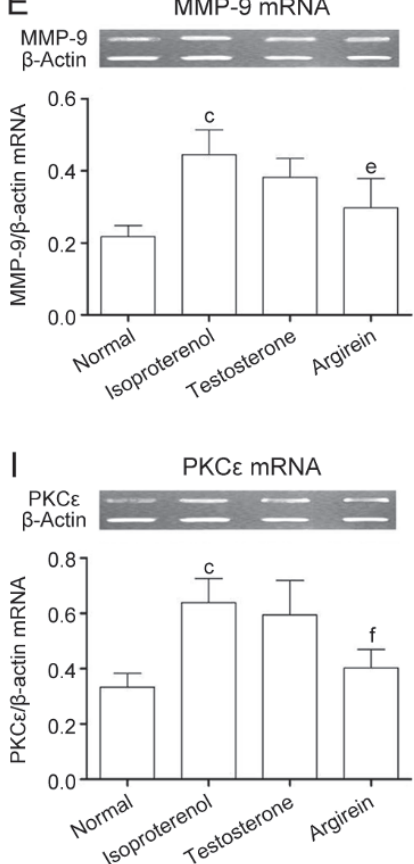

B
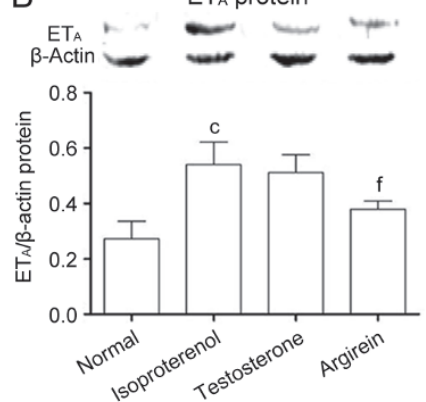

$\mathrm{F}$

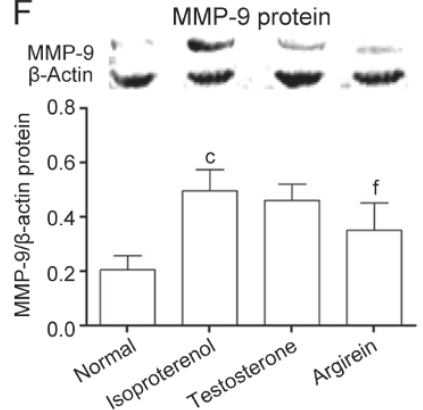

$\mathrm{J}$

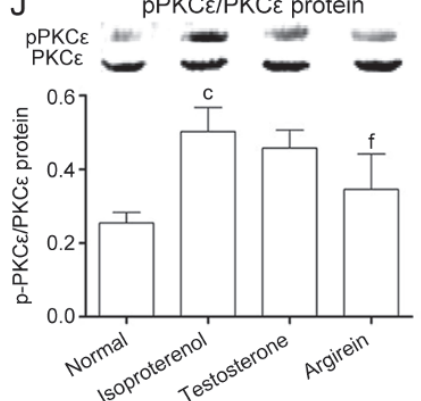

C
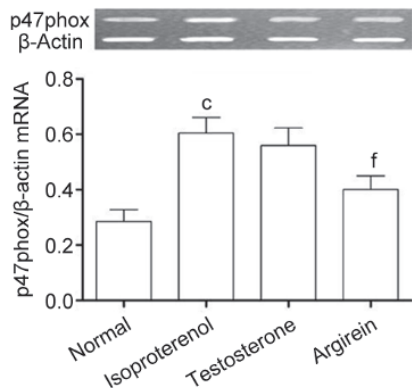

G

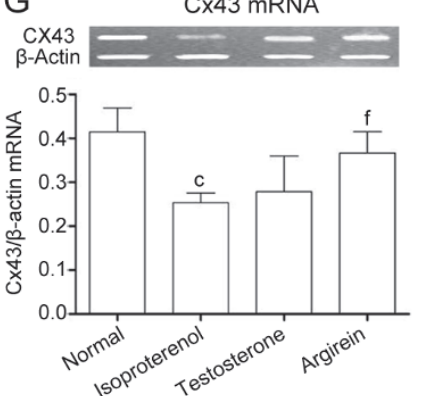

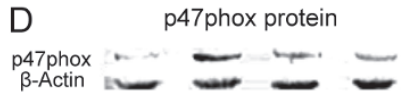

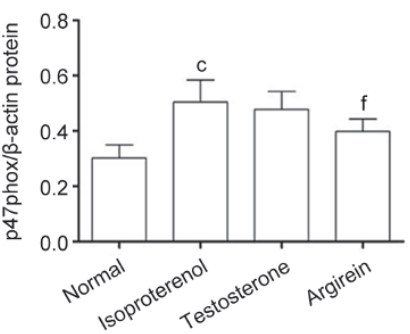

$\mathrm{H}$
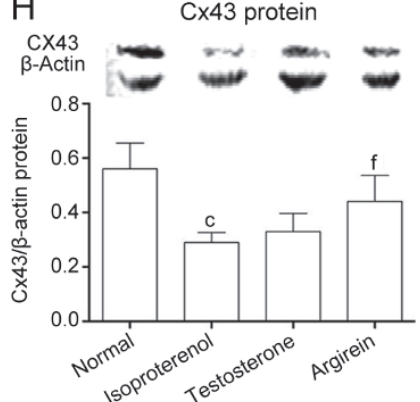

Figure 3. Upregulation of $\mathrm{ET}_{\mathrm{A}} \mathrm{R}\left(\mathrm{ET}_{\mathrm{A}}\right), \mathrm{NADPH}$ oxidase $\mathrm{p} 47 \mathrm{phox}, \mathrm{MMP}$ 9 and PKCE ( $\mathrm{PPKC \varepsilon})$, and downregulation of $\mathrm{Cx} 43$ were found in the ISO injected rats in vivo and were significantly attenuated by argirein, but the hypergonadotrophic rats had no response to testosterone propionate. (A and $B$ ) $\mathrm{ET}_{\mathrm{A}}$; (C and D) NADPH oxidase p47phox; (E, F) MMP-9; (G and H) Cx43; (I and J) PKCE and pPKCE/PKCE. Mean \pm SD. $n=8 .{ }^{c} P<0.01$ vs normal. ${ }^{e} P<0.05,{ }^{f} P<0.01$ vs ISO.

testosterone biosynthesis in the testis ${ }^{[26-27]}$.

A normal ET system is essential to maintain testicular function and morphology. ET-1 rhythmically produced by the seminiferous epithelium and Sertoli's cells initiates rhythmic contractility of the muscle-like cells that surround the tubules, which transports sperm from the testis to the epididymis ${ }^{[28]}$. In adenine medicated rats, the ET system was markedly
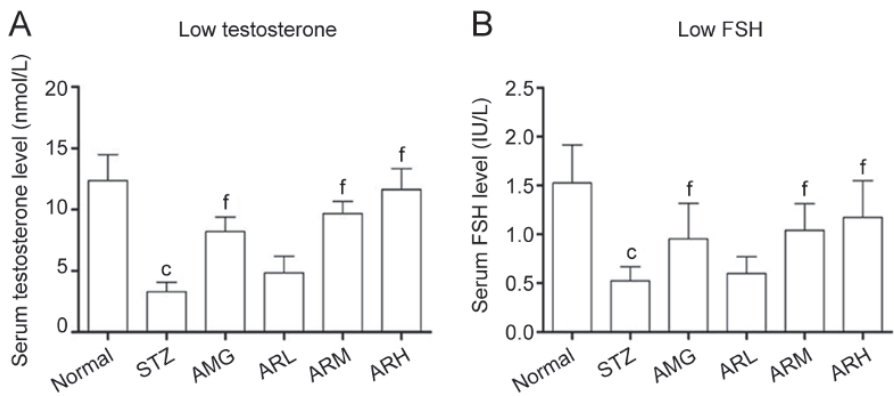

C

Low LH

D

Low serum insulin
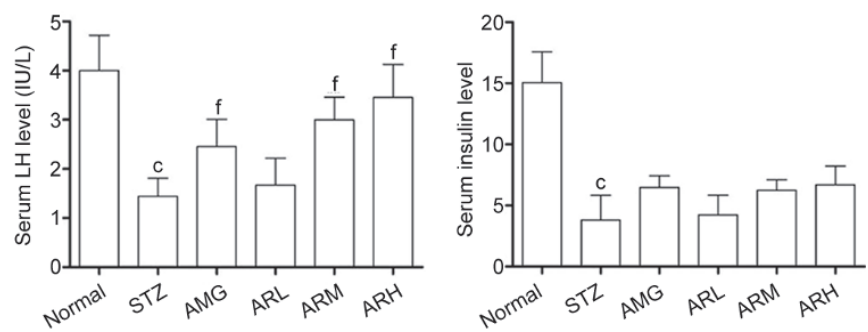

Figure 4. Diabetic testopathy in STZ-injected rats: Decreased testosterone was predominant in association with a decreased FSH and LH in serum, characterized as hypogonadotrophic hypogonadism in rats. The abnormalities were ameliorated significantly by argirein 40,80, and 120 mg $\cdot \mathrm{kg}^{-1} \cdot \mathrm{d}^{-1}$ compared with AMG. (A) Low testosterone; (B) Low FSH; (C) Low LH; (D) Low insulin in serum. Mean \pm SD. $n=8$. ${ }^{\mathrm{c}} P<0.01$ vs normal. ${ }^{\mathrm{f}} P<0.01 \mathrm{vs} \mathrm{STZ.}$ 
A

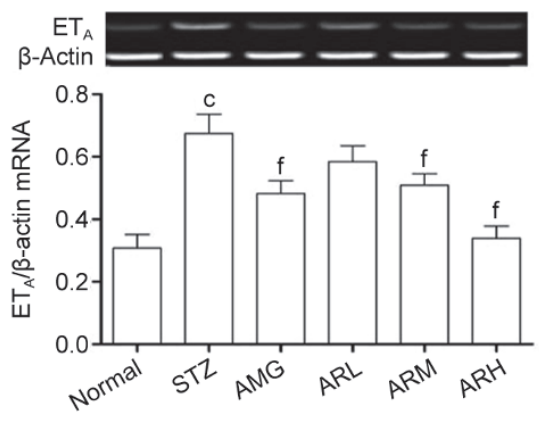

D
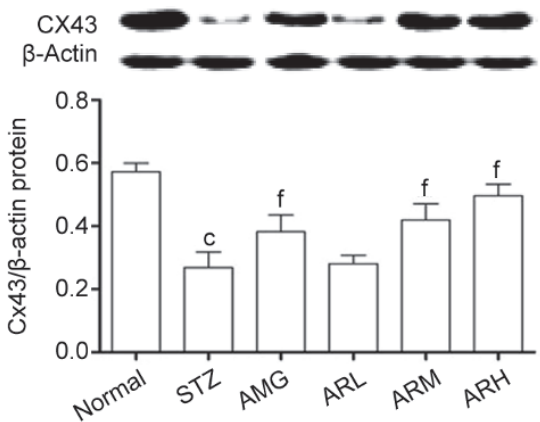

B

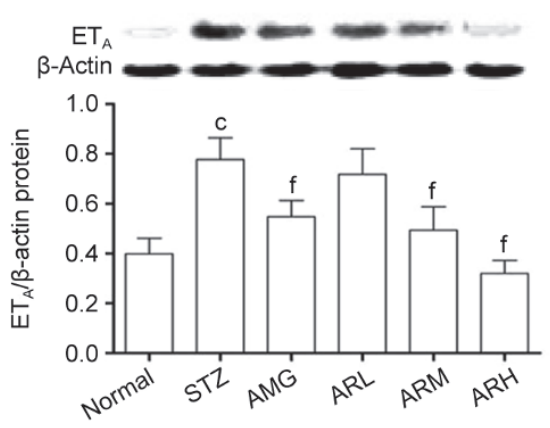

E

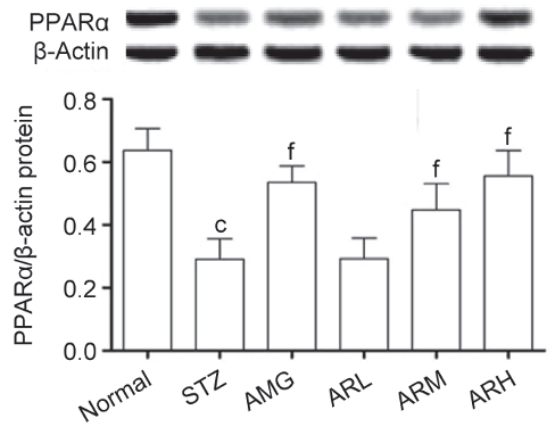

C

Cx43 mRNA

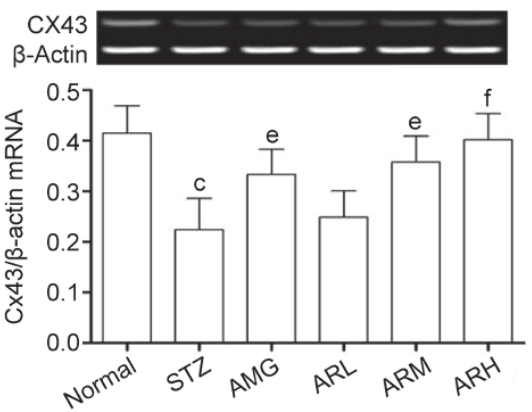

Figure 5. Upregulation of $\mathrm{ET}_{\mathrm{A}} \mathrm{R}\left(\mathrm{ET}_{\mathrm{A}}\right)$ and downregulation of $\mathrm{C} \times 43$ and $\mathrm{PPAR} \alpha$ were found in $\mathrm{STZ}$ injected rats in vivo and were ameliorated significantly by argirein 40,80 , and $120 \mathrm{mg} \mathrm{kg}^{-1} \cdot \mathrm{d}^{-1}$. (A and B) $\mathrm{ET}_{\mathrm{A}} \mathrm{R}$; (C and D) $\mathrm{C} \times 43$; (E) PPAR . Mean \pm SD. $n=8 .{ }^{\mathrm{c}} P<0.01$ vs normal. ${ }^{\mathrm{e}} P<0.05,{ }^{\mathrm{f}} P<0.01$ vs STZ.

A

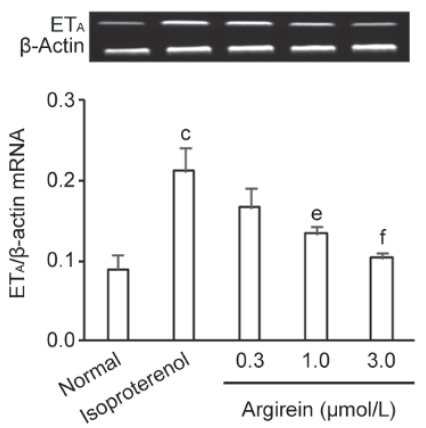

$\mathrm{E}$
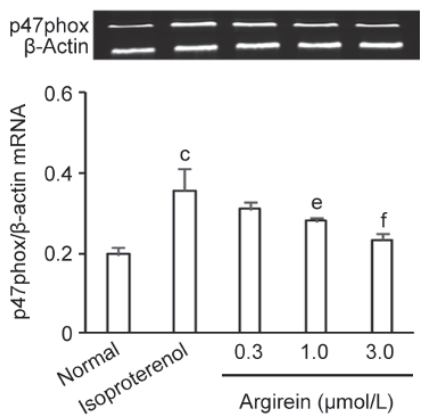

B

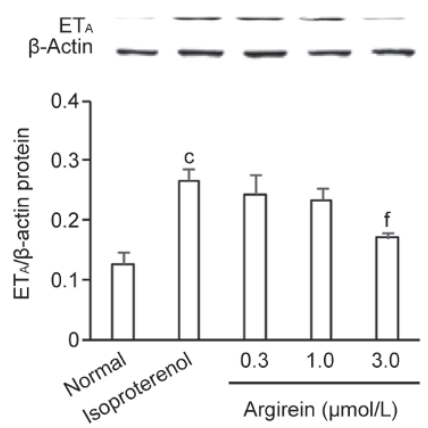

$\mathrm{F}$
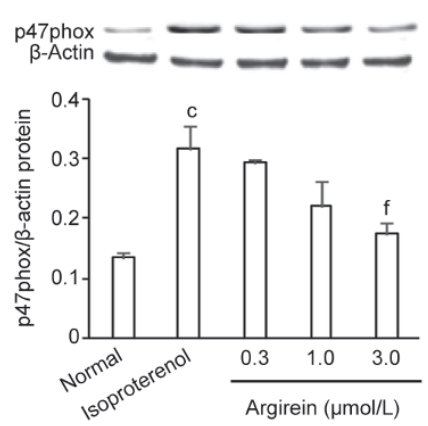

C
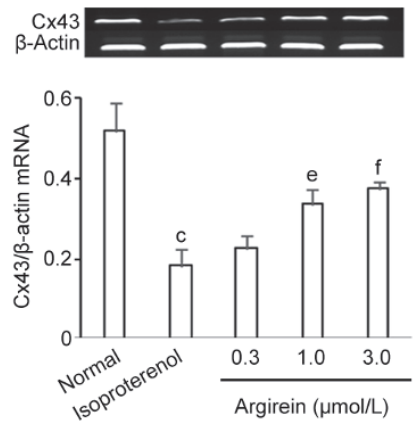

G

Cx43 mRNA

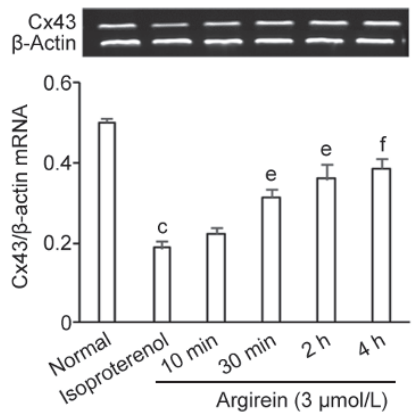

D
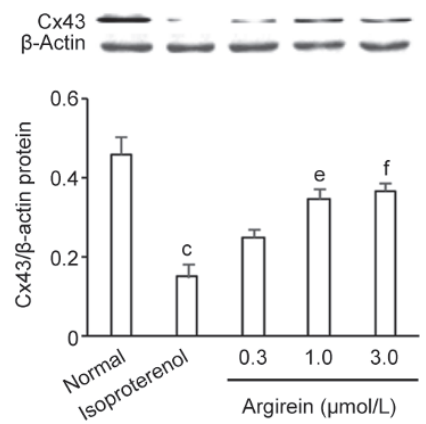

$\mathrm{H}$
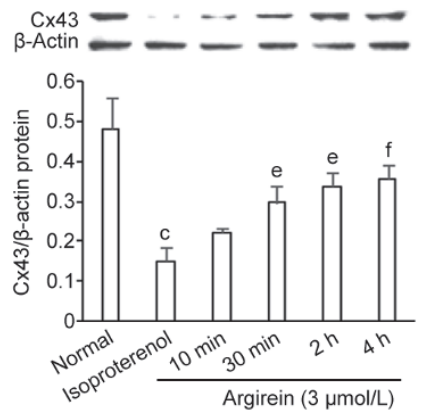

Figure 6. The dose-dependent and time-dependent effects of argirein on isoproterenol (ISO) $1.0 \mu \mathrm{mol} / \mathrm{L}$ incubated testis homogenate in vitro. Up-regulation of $m R N A$ and protein expressions of $\mathrm{ET}_{A} \mathrm{R}\left(\mathrm{ET}_{\mathrm{A}}\right), \mathrm{NADPH}$ oxidase $\mathrm{p} 47$ phox and downregulation of $\mathrm{Cx} 43$ were dose-dependently ameliorated by argirein from 0.3 to $3.0 \mu \mathrm{mol} / \mathrm{L}$. In addition, argirein time-dependently reversed downregulation of mRNA and protein expressions of Cx43 in isoproterenol incubated medium. ( $A$ and $B$ ) Dose-dependent effect of argirein on $\mathrm{ET}_{\mathrm{A}} \mathrm{R}$; ( $\mathrm{C}$ and $\left.\mathrm{D}\right)$ Dose-dependent effect of argirein on $\mathrm{C} \times 43$; ( $\mathrm{E}$ and $\left.\mathrm{F}\right)$ Dose-dependent effect of argirein on p47phox; (G and H) Time-dependent effect of argirein on $\mathrm{Cx} 43$ expression. Mean \pm SD. $n=6 .{ }^{\mathrm{C}} P<0.01$ vs normal. ${ }^{\mathrm{e}} P<0.05,{ }^{\mathrm{f}} P<0.01$ vs ISO. 
A

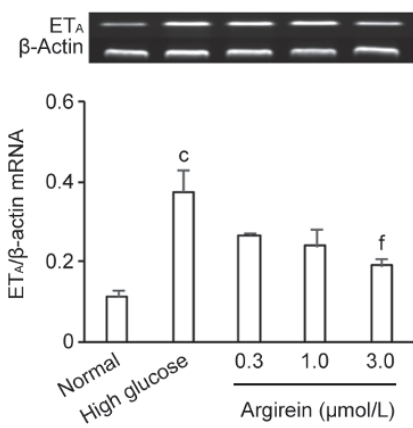

E
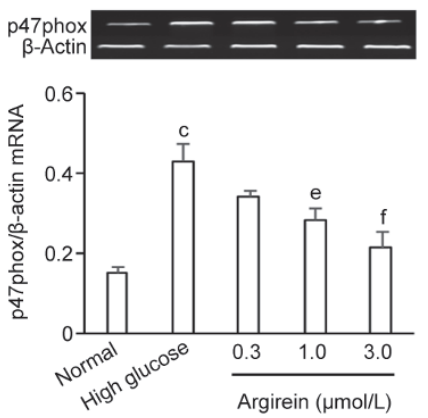

B
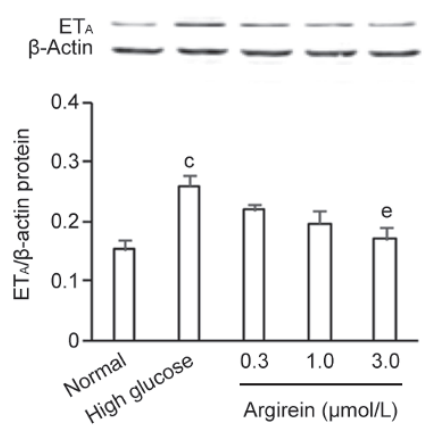

$\mathrm{F}$
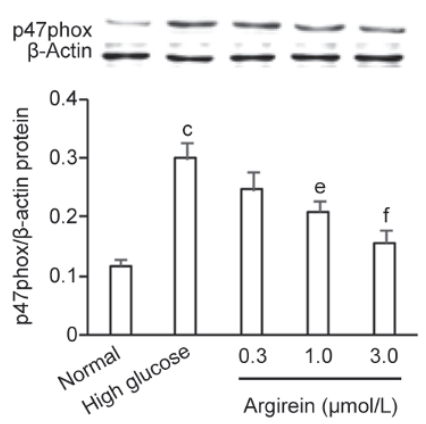

C Cx43

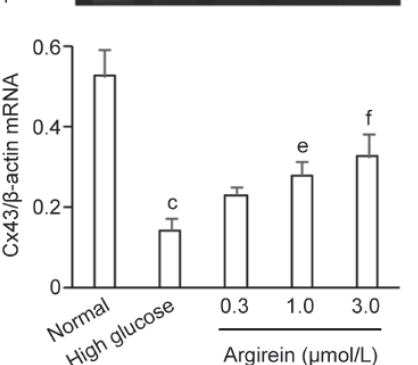

Cx43 mRNA

D
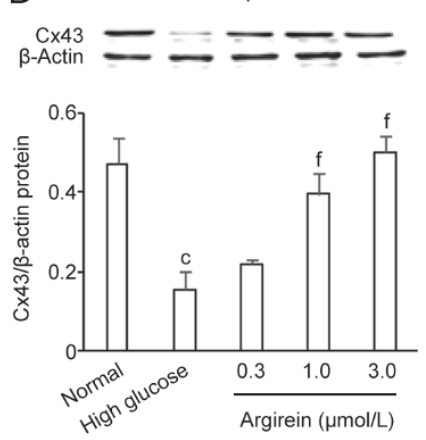

G

CX43 mRNA

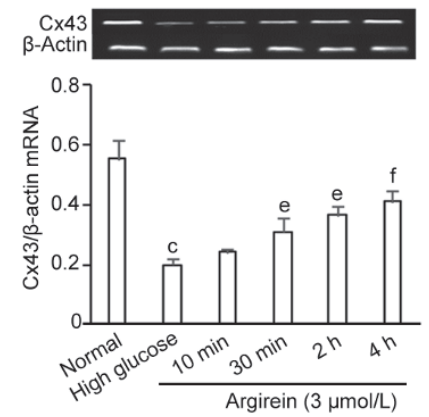

$\mathrm{H}$
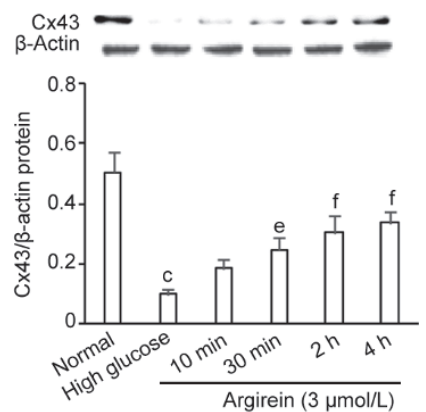

Figure 7. The dose-dependent and time-dependent effects of argirein on high glucose-incubated testis homogenate in vitro. The up-regulation of mRNA and protein expressions of $\mathrm{ET}_{A} \mathrm{R}\left(\mathrm{ET}_{\mathrm{A}}\right), \mathrm{NADPH}$ oxidase $\mathrm{p} 47$ phox and downregulation of $\mathrm{Cx} 43$ were dose-dependently ameliorated from 0.3 to $3.0 \mu \mathrm{mol} / \mathrm{L}$. In addition, argirein time-dependently reversed downregulation of mRNA and protein expressions of $\mathrm{Cx} 43$ in high glucose incubated medium. (A and $\mathrm{B}$ ) Dose-dependent effect of argirein on $\mathrm{ET}_{A} \mathrm{R}$; ( $\mathrm{C}$ and $\mathrm{D}$ ) Dose-dependent effect of argirein on $\mathrm{Cx} 43$; (E, F) Dose-dependent effect of argirein on p47phox; (G and $\mathrm{H}$ ) Time-dependent effect of argirein on $\mathrm{Cx} 43$ expression. Mean $\pm \mathrm{SD}$. $n=6$. ${ }^{\mathrm{b}} P<0.05,{ }^{\mathrm{c}} P<0.01$ vs normal. ${ }^{\mathrm{e}} P<0.05,{ }^{\mathrm{f}} P<0.01$ vs high glucose.

suppressed and associated with serious damage to the testis ${ }^{[11]}$. However, an overactivated ET system has also been demonstrated to cause testis malfunction, which is relevant to the potent contraction of capillaries in the testis and results in an insufficient blood supply ${ }^{[29]}$, the promotion of ROS generation and the subsequent induction of apoptosis of testis cells ${ }^{[14]}$. As demonstrated in the present study, these changes were reproduced by a simple approach that includes the incubation of testis homogenate with ISO or high glucose in vitro, and NOX activation is likely involved independently. The responses to argirein were mild in vitro because the exposure to argirein was brief and occurred in only the last $2 \mathrm{~h}$. In general, the effect of argirein on the diseased testes occurred in a doserelated and time-dependent manner.

Increased MMP-9 expression may induce an abnormality of testicular remodeling, which adversely affects degradation and recombination of the extracellular matrix, and thus relates to fibro-proliferative reactions in testicular tissues ${ }^{[30]}$. It is consistent with our previous findings that ROS and the activated $\mathrm{ET}_{\mathrm{A}}$ regulate MMP-9 to mediate the fibrosis process in the vasculature, as well as diabetic testis ${ }^{[31-33]}$.

In addition to the PKA (protein kinase A) signaling pathway, the $\mathrm{PKC} \varepsilon$ signaling pathway is activated in myocardial cells by ISO, ET-1 or $\mathrm{H}_{2} \mathrm{O}_{2}{ }^{[33]}$. Increased phosphorylated PKC $\varepsilon$ (a ratio of $\mathrm{pPKC} \varepsilon / \mathrm{PKC} \varepsilon$ protein) may predicate an increase in the pro-inflammatory reactions as a result of $\mathrm{ET}_{\mathrm{A}}$ activation, which may represent a potential target for drug intervention to relieve hypergonadotrophic hypogonadism.

Spermatogenesis is continuously subjected to the process of proliferation and differentiation of germ cells, which requires highly coordinated cellular interactions via intercellular junctions. Cx43 is the most abundant protein that communicates signals through gap junctions in the vertebrate testis, and gap junctions between Sertoli cells and spermatogonia are critically involved in controlling germ cell survival ${ }^{[34-35]}$. Abnormal Cx43 participates in diabetic lesions, such as in diabetic nephropathy ${ }^{[36]}$. In this study, the downregulated Cx43 caused by ISO or diabetes in vivo induces basic pathological changes in testis dysfunction. Thus, we confirmed that depressed Cx43 expression is as important as abnormal $\mathrm{ET}_{\mathrm{A}}$ implicated in the defective testis that leads to male hypogonadism, which may occur under physical and mental stress or diabetes mellitus. These changes were relieved by argirein. The beneficial effect of argirein on the diabetic testis was as effective as AMG. Testosterone supplementation did not relieve these changes in the testis, with the exception of correcting serum hormones. Downregulated PPARa is a sign of pathological changes in the testis, and increased PPARa caused by PPARa agonists 
is beneficial to diabetic vascular lesions ${ }^{[37]}$. Furthermore, an upregulation of the decreased PPARa by argirein may indicate an improved capillary circulation in the diabetic testis.

The induction of an abnormal testis via a whole dose of STZ injected in rats is a model of type 1 diabetes, with a significant decrease in serum insulin; the reduced serum insulin did not respond to AMG or argirein. In contrast, the rat model of type 2 diabetes caused by high fat and high sugar and a low STZ dose induced increased insulin in the serum as a result of insulin resistance, which was significantly alleviated by argirein ${ }^{[35]}$.

The theoretical consideration of male hypogonadism is complex, and in our previous study, the abnormal expression of the main genes related to testosterone biosynthesis was due to endoplasmic reticulum stress and NOX activation ${ }^{[10,35]}$. Here, we report that abnormal $\mathrm{ET}_{\mathrm{A}}$ and $\mathrm{CX} 43$ are actively implicated in the diseased testes, which is consistent with the findings in our previous studies ${ }^{[11,38]}$.

Limitations: the in vitro tests reproduce data that resemble the in vivo data; however, we did test in a simply way using testis homogenate instead of the incubation of cells, such as Leydig cells, isolated from the testis ${ }^{[15,35]}$. Thus, the results of the in vitro test do not indicate injury of the reproductive epithelial cells, Sertoli cells or Leydig cells individually; instead, the testis as a whole is considered affected under these conditions.

In summary, in male hypogonadism, an overactivation of the $\mathrm{ET}_{\mathrm{A}}$ pathway with NOX activation is definitely involved in the molecular mechanisms of defective testes that contribute to the two types of male hypogonadism. Argirein is possibly promising in correcting the two types of hypogonadism via the normalization of abnormalities in $\mathrm{ET}_{\mathrm{A}}, \mathrm{NOX}$ and $\mathrm{Cx} 43$ in the affected testis.

\section{Acknowledgements}

This work was supported by the National Natural Science Foundation of China (№ 81570413 and 81070145).

\section{Author contribution}

De-zai DAI designed research; Ming XU, Chen HU, Husseinhamed KHAN, Fang-hong SHI and Qing LI performed research; Xiao-dong CONG contributed new analytical tools and reagents; Yin DAI analyzed data; De-zai DAI and Ming $\mathrm{XU}$ wrote the paper.

\section{Supplementary information}

Supplementary materials were available on Acta Pharmacologica Sinica's web site.

\section{References}

1 Mulligan T, Frick MF, Zuraw QC, Stemhagen A, McWhirter C. Prevalence of hypogonadism in males aged at least 45 years: the HIM study. Int J Clin Pract 2006; 60: 762-9.

2 Dhindsa S, Miller MG, McWhirter CL, Mager DE, Ghanim H, Chaudhuri $\mathrm{A}$, et al. Testosterone concentrations in diabetic and nondiabetic obese men. Diabetes Care 2010; 33: 1186-92.

3 Kvorning T, Christensen LL, Madsen K, Nielsen JL, Gejl KD, Brixen K, et al. Mechanical muscle function and lean body mass during super- vised strength training and testosterone therapy in aging men with low-normal testosterone levels. J Am Geriatr Soc 2013; 61: 957-62.

4 Isidori AM, Giannetta E, Lenzi A. Male hypogonadism. Pituitary 2008; 11: 171-80.

5 Ackerman CM, Lowe LP, Dyer AR, Hayes MG, Metzger BE, Lowe WL, et al. Maternal testosterone levels are associated with C-peptide levels in the Mexican American subset of the Hyperglycemia and Adverse Pregnancy Outcome (HAPO) Study cohort. Horm Metab Res 2013; 45: 617-20.

6 Kang NN, Fu L, Xu J, Han Y, Cao JX, Sun JF, et al. Testosterone improves cardiac function and alters angiotensin II receptors in isoproterenol-induced heart failure. Arch Cardiovasc Dis 2012; 105: 68-76.

7 Khera M, Bhattacharya RK, Blick G, Kushner H, Nguyen D, Miner MM. Improved sexual function with testosterone replacement therapy in hypogonadal men: real-world data from the Testim Registry in the United States (TRiUS). J Sex Med 2011; 8: 3204-13.

8 Jacob BC. Testosterone replacement therapy in males with erectile dysfunction. J Pharm Pract 2011; 24: 298-306.

9 Tang X, Qi M, Dai D, Zhang C. Effects of CPU 86017 (chlorobenzyltetrahydroberberine chloride) and its enantiomers on thyrotoxicosisinduced overactive endothelin-1 system and oxidative stress in rat testes. Urology 2006; 68: 455-61.

10 Zhang GL, Dai DZ, Zhang C, Dai Y. Apocynin and raisanberine alleviate intermittent hypoxia induced abnormal StAR and 3beta-HSD and low testosterone by suppressing endoplasmic reticulum stress and activated p66Shc in rat testes. Reprod Toxicol 2013; 36: 60-70.

11 Feng Y, Zhang Q, Dai DZ, Ying HJ, Dai Y. Strontium fructose 1,6-diphosphate rescues adenine-induced male hypogonadism and upregulates the testicular endothelin-1 system. Clin Exp Pharmacol Physiol 2007; 34: 1131-7.

12 Kaparianos A, Argyropoulou E, Efremidis G, Spiropoulos K. Sex hormone alterations and systemic inflammation in a group of male COPD smokers and their correlation with the +138 ins $A /$ delA endothelin- 1 gene polymorphism. A case-control study. Eur Rev Med Pharmacol Sci 2011; 15: 1149-57.

13 Zhang Q, Liu HR, Ying HJ, Dai DZ, Tang XY, Dai Y. Strontium fructose 1,6-diphosphate alleviates early diabetic testopathy by suppressing abnormal testicular matrix metalloproteinase system in streptozocintreated rats. J Pharm Pharmacol 2009; 61: 229-36.

14 Tang XY, Zhang Q, Dai DZ, Ying HJ, Wang QJ, Dai Y. Effects of strontium fructose 1,6-diphosphate on expression of apoptosis-related genes and oxidative stress in testes of diabetic rats. Int J Urol 2008; 15: 251-6.

15 Lydka M, Bilinska B, Cheng CY, Mruk DD. Tumor necrosis factor alpha-mediated restructuring of the Sertoli cell barrier in vitro involves matrix metalloprotease 9 (MMP-9), membrane-bound intercellular adhesion molecule-1 (ICAM-1) and the actin cytoskeleton. Spermatogenesis 2012; 2: 294-303.

16 Gao Q, Qin WS, Jia ZH, Zheng JM, Zeng CH, Li LS, et al. Rhein improves renal lesion and ameliorates dyslipidemia in $d b / d b$ mice with diabetic nephropathy. Planta Med 2010; 76: 27-33.

17 Jia ZH, Liu ZH, Zheng JM, Zeng CH, Li LS. Combined therapy of rhein and benazepril on the treatment of diabetic nephropathy in $d b / d b$ mice. Exp Clin Endocrinol Diabetes 2007; 115: 571-6.

18 Cong XD, Ding MJ, Dai DZ, Wu Y, Zhang Y, Dai Y. ER stress, p66shc, and $p$-Akt/Akt mediate adjuvant-induced inflammation, which is blunted by argirein, a supermolecule and rhein in rats. Inflammation 2012; 35: 1031-40.

19 Cong XD, Fu PR, Dai DZ, Zhang Y, Dai Y. Pharmacokinetic behavior of argirein, derived from rhein, is characterized as slow release and prolonged T1/2 of rhein in rats. Eur J Pharm Sci 2012; 46: 468-74. 
20 Sanchez A, Martinez P, Munoz M, Benedito S, Garcia-Sacristan A, Hernandez M, et al. Endothelin-1 contributes to endothelial dysfunction and enhanced vasoconstriction through augmented superoxide production in penile arteries from insulin-resistant obese rats: role of $\mathrm{ET}_{\mathrm{A}}$ and $\mathrm{ET}_{\mathrm{B}}$ receptors. Br J Pharmacol 2014; 171: 5682-95.

21 Peng HJ, Dai DZ, Ji H, Dai Y. The separate roles of endothelin receptors participate in remodeling of matrix metalloproteinase and connexin 43 of cardiac fibroblasts in maladaptive response to isoproterenol. Eur J Pharmacol 2010; 634: 101-6.

22 Di Naso FC, Forgiarini Junior LA, Forgiarini LF, Porawski M, Dias AS, Marroni NA. Aminoguanidine reduces oxidative stress and structural lung changes in experimental diabetes mellitus. J Bras Pneumol 2010; 36: 485-9.

23 Groemping Y, Lapouge K, Smerdon SJ, Rittinger K. Molecular basis of phosphorylation-induced activation of the NADPH oxidase. Cell 2003; 113: 343-55.

24 Youn JY, Gao L, Cai $\mathrm{H}$. The p47phox- and NADPH oxidase organiser 1 (NOXO1)-dependent activation of NADPH oxidase 1 (NOX1) mediates endothelial nitric oxide synthase (eNOS) uncoupling and endothelial dysfunction in a streptozotocin-induced murine model of diabetes. Diabetologia 2012; 55: 2069-79.

25 El-Benna J, Dang PM, Gougerot-Pocidalo MA. Priming of the neutrophil NADPH oxidase activation: role of p47phox phosphorylation and NOX2 mobilization to the plasma membrane. Semin Immunopathol 2008; 30: 279-89.

26 Kefer JC, Agarwal A, Sabanegh E. Role of antioxidants in the treatment of male infertility. Int J Urol 2009; 16: 449-57.

27 Aitken RJ, Smith TB, Jobling MS, Baker MA, De luliis GN. Oxidative stress and male reproductive health. Asian J Androl 2014; 16: 31-8.

28 Cellini M, Versura P, Zamparini E, Bendo E, Campos EC. Effects of endothelin-1 and flunarizine on human trabecular meshwork cell contraction. Exp Biol Med (Maywood) 2006; 231: 1081-4.

29 Lo AC, Fung MK, Au CL, Chan TS, Sauer B, Chung SS, et al. Transgenic mice over-expressing endothelin-1 in testis transactivated by a Cre/ loxP system showed decreased testicular capillary blood flow. Transgenic Res 2004; 13: 119-34.

30 Chaves-Pozo E, Castillo-Briceno P, Garcia-Alcazar A, Meseguer J,
Mulero V, Garcia-Ayala A. A role for matrix metalloproteinases in granulocyte infiltration and testicular remodelation in a seasonal breeding teleost. Mol Immunol 2008; 45: 2820-30.

31 Liu HR, Tang XY, Dai DZ, Dai Y. Ethanol extracts of Rehmannia complex (Di Huang) containing no Corni fructus improve early diabetic nephropathy by combining suppression on the ET-ROS axis with modulate hypoglycemic effect in rats. J Ethnopharmacol 2008; 118: 466-72.

32 Xu J LN, Dai DZ, Yu F, Dai Y. The endothelin receptor antagonist CPU0213 is more effective than aminoguanidine to attenuate isoproterenol-induced vascular abnormality by suppressing overexpression of NADPH oxidase [correction of oxidas], $\mathrm{ET}_{\mathrm{A}}, \mathrm{ET}_{\mathrm{B}}$, and MMP9 in the vasculature. J Cardiovasc Pharmacol 2008; 52: 42-8.

33 Li N, Jia N, Dai DZ, Dai Y. Endothelin receptor antagonist CPU0213 and vitamin E reverse downregulation of FKBP12.6 and SERCA2a: a role of hyperphosphorylation of PKCepsilon. Eur J Pharmacol 2008; 591: 211-8.

34 Gilleron J, Malassine A, Carette D, Segretain D, Pointis G. Chemical connexin impairment in the developing gonad associated with offspring infertility. Curr Med Chem 2011; 18: 5145-58.

35 Liu GL, Zhang YM, Dai DZ, Ding MJ, Cong XD, Dai Y. Male hypogonadism induced by high fat diet and low dose streptozotocin is mediated by activated endoplasmic reticulum stress and IkappaBbeta and attenuated by argirein and valsartan. Eur J Pharmacol 2013; 713: $78-88$.

$36 \mathrm{Hu}$ C, Cong XD, Dai DZ, Zhang Y, Zhang GL, Dai Y. Argirein alleviates diabetic nephropathy through attenuating NADPH oxidase, $\mathrm{Cx} 43$, and PERK in renal tissue. Naunyn Schmiedebergs Arch Pharmacol 2011; 383: 309-19.

37 Ding L, Cheng R, Hu Y, Takahashi Y, Jenkins AJ, Keech AC, et al. Peroxisome proliferator-activated receptor alpha protects capillary pericytes in the retina. Am J Pathol 2014; 184: 2709-20.

38 Cheng YS, Dai DZ, Dai Y. Testis dysfunction by isoproterenol is mediated by upregulating endothelin receptor A, leptin and protein kinase Cvarepsilon and is attenuated by an endothelin receptor antagonist CPU0213. Reprod Toxicol 2010; 29: 421-6. 